\title{
Effect of feeding modality on interstage growth after stage $I$ palliation: A report from the National Pediatric Cardiology Quality Improvement Collaborative
}

\author{
Garick D. Hill, MD, ${ }^{a}$ David A. Hehir, MD, ${ }^{b}$ Peter J. Bartz, MD, ${ }^{a, f}$ Nancy A. Rudd, MS, CPNP, ${ }^{a}$ \\ Michele A. Frommelt, MD, ${ }^{a}$ Julie Slicker, MS, RD, ${ }^{a}$ Jena Tanem, MS, APNP, ${ }^{a}$ Katherine Frontier, MS, \\ Qun Xiang, MS, ${ }^{\mathrm{d}}$ Tao Wang, PhD, ${ }^{\mathrm{d}}$ James S. Tweddell, MD, ${ }^{\mathrm{e}}$ and Nancy S. Ghanayem, MD ${ }^{\mathrm{b}}$
}

\begin{abstract}
Objectives: Achieving adequate growth after stage 1 palliation for children with single-ventricle heart defects often requires supplemental nutrition through enteral tubes. Significant practice variability exists between centers in the choice of feeding tube. The impact of feeding modality on the growth of patients with a single ventricle after stage 1 palliation was examined using the multiinstitutional National Pediatric Cardiology Quality Improvement Collaborative data registry.
\end{abstract}

\begin{abstract}
Methods: Characteristics of patients were compared by feeding modality, defined as oral only, nasogastric tube only, oral and nasogastric tube, gastrostomy tube only, and oral and gastrostomy tube. The impact of feeding modality on change in weight for age z-score during the interstage period, from stage 1 palliation discharge to stage 2 palliation, was evaluated by multivariable linear regression, adjusting for important patient characteristics and postoperative morbidities.
\end{abstract}

\begin{abstract}
Results: In this cohort of 465 patients, all groups demonstrated improved weight for age z-score during the interstage period with a mean increase of $0.3 \pm 0.8$. In multivariable analysis, feeding modality was not associated with differences in the change in weight for age z-score during the interstage period $(P=.72)$. Risk factors for poor growth were a diagnosis of hypoplastic left heart syndrome $(P=.003)$, vocal cord injury $(P=.007)$, and lower target caloric goal at discharge $(P=.001)$.

Conclusions: In this large multicenter cohort, interstage growth improved for all groups and did not differ by feeding modality. With appropriate caloric goals and interstage monitoring, adequate growth may be achieved regardless of feeding modality and therefore local comfort and complication risk should dictate feeding modality. (J Thorac Cardiovasc Surg 2014;148:1534-9)
\end{abstract}

\begin{abstract}
Although operative survival continues to improve after stage 1 palliation (S1P) for children with single-ventricle heart lesions, the interstage period, from discharge after S1P until stage 2 palliation ( $\mathrm{S} 2 \mathrm{P})$, continues to be a high-risk time with reported mortality of $2 \%$ to $20 \%,{ }^{1-6}$ Growth and feeding problems are common in these infants and may have a significant impact on outcomes. ${ }^{7-10}$ Historically, patients with hypoplastic left heart syndrome (HLHS) and other single-ventricle variants requiring S1P have demonstrated poor growth during neonatal hospitalization and the interstage period; this has been attributed to a variety of factors, including high metabolic demands in the face of inadequate oral intake as well as the inability to safely feed

From the Divisions of Cardiology, ${ }^{a}$ Critical Care, ${ }^{b}$ and Speech and Audiology, Department of Pediatrics; Division of Biostatistics ${ }^{\mathrm{d}}$; Division of Cardiothoracic Surgery, ${ }^{\mathrm{e}}$ Department of Surgery; and Division of Adult Cardiovascular Medicine, ${ }^{\mathrm{f}}$ Department of Internal Medicine, Medical College of Wisconsin, Milwaukee, Wis. Disclosures: Authors have nothing to disclose with regard to commercial support.

Received for publication Sept 24, 2013; revisions received Dec 30, 2013; accepted for publication Feb 3, 2014; available ahead of print March 4, 2014.

Address for reprints: Garick D. Hill, MD, $9000 \mathrm{~W}$ Wisconsin Ave, Milwaukee, WI 53226 (E-mail: ghill@chw.org).

0022-5223/\$36.00

Copyright (c) 2014 by The American Association for Thoracic Surgery

http://dx.doi.org/10.1016/j.jtcvs.2014.02.025
\end{abstract}

by mouth because of comorbidities. Previous studies have demonstrated that to ensure normal growth, $18 \%$ to $75 \%$ of patients require supplementation with either nasogastric (NG) or gastrostomy tube (GT) at the time of discharge after S1P. $7,11,12$ The implementation of an interstage homemonitoring program including daily recording of weight and intake has been associated with improved survival as well as normal growth outcomes, and has been adopted by many programs. ${ }^{9,12-15}$ There is considerable variation in feeding modality chosen when supplementation is required, and there may be important differences between children able to feed orally versus those fed via NG or GT. ${ }^{9,14,16-18}$ The inability to achieve normal growth and to feed orally may be surrogates of more severe illness and vulnerability. ${ }^{2,12,19-21}$ Recent single-center studies have demonstrated conflicting results for morbidity and mortality in patients with a single ventricle fed by $\mathrm{NG}$ versus GT. $^{2,10,19,22}$ No study to date has compared growth between feeding modalities in patients with a single ventricle using multiinstitutional data.

The National Pediatric Cardiology Quality Improvement Collaborative (NPC-QIC) is a multicenter quality improvement collaborative with a primary aim "To reduce mortality 


\section{Abbreviations and Acronyms \\ $\mathrm{ECMO}=$ extracorporeal membrane oxygenation \\ $\mathrm{GT}=$ gastrostomy tube \\ HLHS $=$ hypoplastic left heart syndrome \\ $\mathrm{NG}=$ nasogastric \\ $\mathrm{PO}=$ oral \\ $\mathrm{S} 1 \mathrm{P}=$ stage 1 palliation \\ S12 = stage 2 palliation \\ $\mathrm{WAZ}=$ weight for age $\mathrm{z}$-score}

and improve the quality of life in infants with HLHS during the interstage period." 23 Based on previous studies demonstrating an association between growth and improved outcomes, the NPC-QIC has identified improvement in interstage growth as a primary driver to achieve improved overall outcomes. $^{23}$ Using data from 47 institutions contributing to the NPC-QIC, we sought to (1) describe the differences in patient characteristics between feeding modality groups, and (2) compare growth outcomes during the interstage period by feeding modality.

\section{METHODS}

\section{Study Design and Measurements}

This was a retrospective analysis of patients enrolled in the NPC-QIC registry. The NPC-QIC is a collaborative of 47 pediatric cardiac programs that includes a voluntary registry of patients discharged home after S1P, which includes surgical palliation or the hybrid alternative. Individual participating sites obtain institutional review board approval and parental informed consent. There is a standard dataset with data definitions, online web-based data entry, and data quality checks. The deidentified data are housed in a secure server at the James M. Anderson Center for Health Systems Excellence at Cincinnati Children's Hospital Medical Center. Individual programs complete detailed data forms consisting of demographic data, birth information, surgical information, as well as clinical variables collected at the time of discharge and at each subsequent visit until discharge from S2P.

Patients completing S2P between June 2008 and July 2012 were included. Interstage deaths were excluded. The cohort was divided into 5 groups based on the feeding modality at discharge from S1P: (1) those fed exclusively by mouth (PO only); (2) exclusively by NG tube (NG only); (3) by a combination of oral and NG tube (PO + NG); (4) exclusively by GT (GT only); and (5) a combination of oral and GT (PO + GT). Indications for preferred feeding modality and morbidity associated with specific enteral tubes were not available in the database.

Demographic data collected were limited to gender and race/ethnicity, which was categorized as white, black or African American, Hispanic, or other. Preoperative factors collected included gestational age, cardiac diagnosis, which for analysis was dichotomized to HLHS versus nonHLHS, the presence of any known genetic syndrome or other chromosomal anomaly, as well as the presence of any other organ system anomalies. Preoperative risk factors recorded were mechanical ventilation and a composite complication variable that included preoperative arrhythmias requiring treatment, shock or acidosis, renal insufficiency, septicemia, necrotizing enterocolitis, and seizures. Postoperative complications were considered as the need for extracorporeal membrane oxygenation (ECMO), prolonged mechanical ventilation ( $>14$ days), vocal cord paralysis, or a composite variable consisting of cardiac arrest, arrhythmia requiring therapy, pneumonia or tracheitis, acute renal failure, wound infection or mediastinitis, diaphragm paralysis, seizures, or necrotizing enterocolitis. Feeding method at discharge from S1P and readmission for $\mathrm{S} 2 \mathrm{P}$ as well as target caloric intake at both times were recorded. Anthropomorphic data included weight at birth, at discharge from S1P, and at readmission for S2P. These were converted to weight for age $\mathrm{z}$-scores (WAZ) to adjust for variation in ages.

\section{Statistical Analysis}

Descriptive data are presented as count and percentage, mean with standard deviation, or median with range as appropriate. For the purposes of analysis, feeding modality at the time of discharge was used as the grouping variable. Comparison between groups for categorical data was performed using the $\chi^{2}$ test or the Fisher exact test where required by insufficient numbers, and analysis of variance or the Kruskal-Wallis test for continuous data based on distribution. Multivariable linear regression was used to determine the risk factors for poor interstage growth. All statistical analyses were performed using SAS version 9.2 (SAS Institute Inc, Cary, NC).

\section{RESULTS}

A total of 465 patients who completed S2P had their weight documented at the time of S2P and were included in the study. At S1P discharge, 56\% required supplementation of intake with a feeding tube; the feeding group breakdown is shown in Figure 1. There was improvement in oral intake during the interstage period with a decrease to $37 \%$ requiring supplementation at the time of S2P, with significant crossover between groups. Within the cohort, 193 of $465(41.5 \%)$ patients had a change in their feeding modality during the interstage period; the $\mathrm{PO}+\mathrm{NG}$ group accounted for $90(47 \%)$ of those 193 patients. A GT was placed during the interstage period in 23 patients. The indications for a change in feeding modality are not documented in the NPC-QIC database.

Comparison of characteristics between groups can be seen in Table 1. Preoperatively, the NG only, GT only, and $\mathrm{PO}+\mathrm{GT}$ groups were more likely to have other organ system anomalies and the GT only group was more likely to require preoperative mechanical ventilation. Postoperatively, compared with the PO only group, those

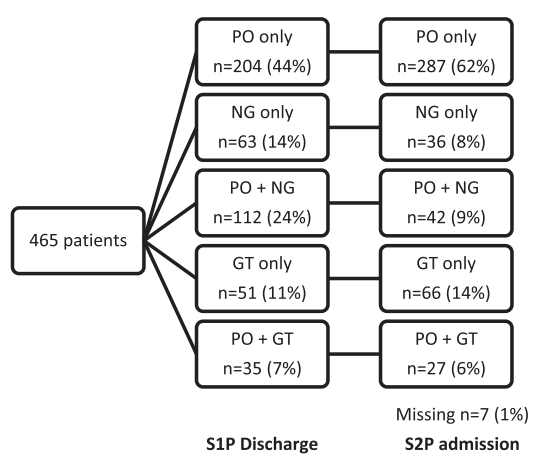

FIGURE 1. Number of patients by feeding modality at discharge and at admission for S2P. $P O$, Oral; $N G$, nasogastric; $G T$, gastrostomy tube; $S 1 P$, stage 1 palliation; $S 2 P$, stage 2 palliation. 
TABLE 1. Characteristics by feeding modality: comparison of feeding groups in univariate analysis

\begin{tabular}{|c|c|c|c|c|c|c|c|}
\hline & $\begin{array}{c}\text { Overall } \\
(n=465)\end{array}$ & $\begin{array}{l}\text { PO only } \\
(n=204)\end{array}$ & $\begin{array}{l}\text { NG only } \\
(n=63)\end{array}$ & $\begin{array}{c}P O+N G \\
(n=112)\end{array}$ & $\begin{array}{l}\text { GT only } \\
(\mathbf{n}=51)\end{array}$ & $\begin{array}{c}\mathbf{P O}+\mathbf{G T} \\
(\mathbf{n}=\mathbf{3 5})\end{array}$ & $\begin{array}{c}P \\
\text { value* }\end{array}$ \\
\hline Male gender, n (\%) & $293(63)$ & $136(67)$ & $40(63)$ & $69(61)$ & $25(49)$ & $23(66)$ & .22 \\
\hline Race/ethnicity, n (\%) & & & & & & & .14 \\
\hline White & $285(61)$ & $121(60)$ & $36(57)$ & $82(73)$ & $25(49)$ & $21(60)$ & \\
\hline Black & $70(15)$ & $29(14)$ & $12(19)$ & $12(11)$ & $11(22)$ & $6(17)$ & \\
\hline Hispanic & $97(21)$ & $48(24)$ & $13(21)$ & $16(14)$ & $13(25)$ & $7(20)$ & \\
\hline Other & $13(3)$ & $6(2)$ & $2(3)$ & $2(2)$ & $2(4)$ & $1(3)$ & \\
\hline HLHS, n (\%) & $302(65)$ & $133(65)$ & $35(56)$ & $75(66)$ & $37(73)$ & $22(63)$ & .42 \\
\hline Genetic syndrome, n (\%) & $32(7)$ & $13(7)$ & $3(5)$ & $7(6)$ & $8(16)$ & $1(3)$ & .1 \\
\hline Other anomaly, n (\%) & $51(11)$ & $18(9)^{1}$ & $10(16)^{2}$ & $7(6)^{1}$ & $10(21)^{2}$ & $6(17)^{2}$ & .03 \\
\hline Preoperative ventilation, $\mathrm{n}(\%)$ & $164(35)$ & $61(30)^{1}$ & $25(40)^{1}$ & $36(32)^{1}$ & $30(59)^{2}$ & $12(34)^{1}$ & .003 \\
\hline S1P type, n (\%) & & & & & & & .004 \\
\hline Norwood + BT shunt & $150(32)$ & $74(36)^{1,2}$ & $14(22)^{3}$ & $30(27)^{1,3}$ & $22(43)^{2,4}$ & $10(29)^{1,2,3,4}$ & \\
\hline Norwood + RV-PA & $260(56)$ & $97(48)^{1}$ & $44(70)^{2}$ & $75(67)^{2}$ & $23(45)^{1}$ & $21(60)^{1}$ & \\
\hline Hybrid procedure & $33(7)$ & $22(11)^{1}$ & $4(6)^{1,2}$ & $1(1)^{2}$ & $5(10)^{1}$ & $1(3)^{1,2}$ & \\
\hline Other & $21(5)$ & $10(5)$ & $1(2)$ & $6(5)$ & $1(2)$ & $3(9)$ & \\
\hline Postoperative ECMO, n (\%) & $28(6)$ & $5(2)^{1}$ & $4(6)^{1,2}$ & $7(6)^{1,2}$ & $7(14)^{2}$ & $5(14)^{2}$ & .004 \\
\hline Post operative ventilation $>14 \mathrm{~d}, \mathrm{n}(\%)$ & $59(13)$ & $14(7)^{1}$ & $13(21)^{2}$ & $9(8)^{1}$ & $15(29)^{2}$ & $8(23)^{2}$ & $<.0001$ \\
\hline Vocal cord paralysis, $\mathrm{n}(\%)$ & $47(10)$ & $13(6)^{1,2}$ & $9(14)^{1,3}$ & $5(4)^{2}$ & $14(27)^{3}$ & $6(17)^{3}$ & $<.0001$ \\
\hline Birth WAZ, mean \pm SD & $-0.5 \pm 0.9$ & $-0.5 \pm 0.9$ & $-0.5 \pm 1.1$ & $-0.5 \pm 0.8$ & $-0.4 \pm 1.2$ & $-0.3 \pm 0.9$ & .51 \\
\hline $\mathrm{S} 1 \mathrm{P}$ discharge $\mathrm{WAZ}$, mean $\pm \mathrm{SD}$ & $-1.5 \pm 0.9$ & $-1.5 \pm 0.8$ & $-1.5 \pm 1.2$ & $-1.5 \pm 0.8$ & $-1.8 \pm 1.2$ & $-1.4 \pm 1.1$ & .16 \\
\hline $\mathrm{S} 2 \mathrm{P}$ WAZ, mean $\pm \mathrm{SD}$ & $-1.3 \pm 1.1$ & $-1.2 \pm 1$ & $-1.3 \pm 1.2$ & $-1.3 \pm 1$ & $-1.5 \pm 1.6$ & $-1.0 \pm 1.2$ & .27 \\
\hline Age at S2P, median d (range) & $150(76-652)$ & $153(76-652)^{1,2}$ & $140(86-373)^{1}$ & $141(78-295)^{1}$ & $163(91-344)^{2}$ & $160(96-267)^{1,2}$ & $<.0001$ \\
\hline Interstage WAZ change, mean \pm SD & $0.3 \pm 0.8$ & $0.3 \pm 0.8$ & $0.3 \pm 0.8$ & $0.3 \pm 0.8$ & $0.3 \pm 1$ & $0.4 \pm 0.9$ & .93 \\
\hline
\end{tabular}

For statistically different characteristics, superscript numbers $\left({ }^{1-4}\right)$ are shared by groups that are not statistically different and those without shared numbers are statistically different. $P O$, Oral; $N G$, nasogastric; $G T$, gastrostomy tube; $H L H S$, hypoplastic left heart syndrome; $S 1 P$, stage 1 palliation; $B T$, Blalock-Taussig; $R V-P A$, right ventriclepulmonary artery; $E C M O$, extracorporeal membrane oxygenation; $W A Z$, weight for age z-score; $S D$, standard deviation; $S 2 P$, stage 2 palliation. $* P$ value for a difference between any group obtained by $\chi^{2}$ test or Fisher exact test for categorical data and analysis of variance or Kruskal-Wallis test for continuous variables.

in the GT only and PO + GT groups more frequently required ECMO and had vocal cord paralysis. There were statistically significant differences in the types of S1P performed by feeding modality but no clear pattern was evident.

Mean weight gain was $7.7 \pm 13 \mathrm{~g} / \mathrm{d}$ from birth to discharge after S1P, at a mean age of $42.4 \pm 27.7$ days. All groups had a decrease in WAZ during this period; the mean WAZ at birth was $-0.5 \pm 1.0$ and the mean WAZ at discharge was $-1.5 \pm 0.9$. During the interstage period, the mean weight gain improved to $22.4 \pm 6.5 \mathrm{~g} / \mathrm{d}$ with a mean change in WAZ of $0.3 \pm 0.8$ during this period, resulting in a final mean WAZ of $-1.3 \pm 1.1$ at $\mathrm{S} 2 \mathrm{P}$. Growth by feeding modality from birth to $\mathrm{S} 2 \mathrm{P}$ is presented in Figure 2. There was no difference in the change in WAZ between groups $(P=.96)$ during the interstage period. Mean target caloric goal at discharge from S1P was $120 \pm 12.5 \mathrm{kcal} / \mathrm{kg} / \mathrm{d}$.

Figure 3 displays the time spent in the hospital, intubated, and in the interstage period between groups. Patients in the GT only and PO + GT groups had significantly longer periods of intubation $(P<.001)$ and longer hospitalization after S1P $(P<.001)$. In multivariable analysis (adjusted $\left.\mathrm{R}^{2}=0.07\right)$, the effect of feeding modality on change in WAZ was not significant $(P=.79)$. Significant risk factors for worse growth were a diagnosis of HLHS $(P=.002)$, a diagnosis of vocal cord injury $(P=.007)$, and having a lower documented target caloric intake at discharge from S1P $(P=.001)$. All factors included in the initial model are presented in Table 2. The mean difference between change in WAZ during the interstage period for those with a diagnosis of HLHS versus those without was -0.3 (95\% confidence interval, -0.6 to -0.1$)$ and -0.5 (95\% confidence interval -0.8 to -0.1$)$ for vocal cord injury versus those without vocal cord injury. For every $10 \mathrm{kcal} / \mathrm{kg} / \mathrm{d}$ increase in target caloric intake at discharge, there was an increase of 0.15 in the WAZ at readmission for S2P.

\section{DISCUSSION}

In this large multiinstitutional database review of infants with single-ventricle heart disease, there was a positive change in WAZ during the interstage period across all groups. Interstage growth was found to be the same between feeding groups with no growth advantage found in selecting one mode of supplemental tube feeding over another. This result is important given the focus on nutrition and growth in this population, and the impact of normal growth on improving outcomes. In addition, previous research has highlighted the considerable variability in practice between 


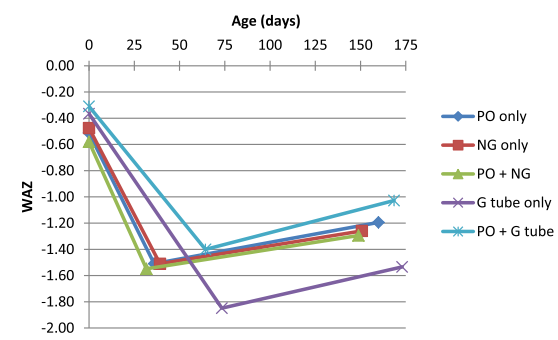

FIGURE 2. Change in WAZ over time. Weights shown were obtained at birth, S1P discharge, and S2P admission. $P O$, Oral; $N G$, nasogastric; $G$, gastrostomy; $W A Z$, weight for age z-score.

centers with regard to the choice of feeding modality when supplementation by feeding tube is required. ${ }^{7,10,12,17,24}$ The reasons for this variability are unclear, and may represent differences in patient characteristics as well as individual provider or center-specific practice patterns and preferences when submitting high-risk patients for elective noncardiac surgery. This analysis was not designed to test differences in morbidities specific to the choice of feeding modality, such as complications related to feeding tube placement. However, this description of the characteristics of a large cohort helps to define the needs of this vulnerable patient population and predict those patients most at risk for poor outcomes.

Before the use of home-monitoring programs for infants with single-ventricle heart disease, growth failure during the interstage period was a frequent finding of interstage outcome studies. ${ }^{7,12-14,17,25-27}$ A typical growth pattern for these patients has emerged from numerous studies, characterized by a large decrease in WAZ from birth to S1P discharge, followed by a less precipitous but continued decline in WAZ during the interstage period. ${ }^{12,14,17,26,27}$ Previous data have shown the consequence of poor weight gain as poor growth and feeding problems are associated with earlier S2P, longer hospitalization after S2P, and higher mortality. ${ }^{7,9}$ However, recent single-center experience from programs using home-monitoring programs with intense nutritional monitoring and intervention demonstrate that catch up

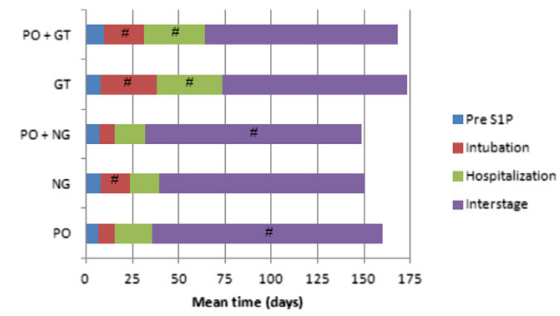

FIGURE 3. Duration of pre-S1P period, intubation, hospitalization, and interstage period by feeding modality at discharge from stage 1 palliation. \#Significantly longer interval $(P<.05)$ than other groups by analysis of variance. $P O$, Oral; $G T$, gastrostomy tube; $N G$, nasogastric; $S 1 P$, stage 1 palliation.
TABLE 2. Risk factors for worse growth

\begin{tabular}{lc}
\hline \multicolumn{1}{c}{ Factor } & $\boldsymbol{P}$ value \\
\hline Feeding modality & .72 \\
Hypoplastic left heart syndrome & .003 \\
Vocal cord paralysis & .007 \\
Lower caloric goal at discharge & .001 \\
Gender & NS \\
Race/ethnicity & NS \\
Presence of a genetic syndrome & NS \\
Other organ system anomaly & NS \\
S1P type & NS \\
Postoperative ECMO & NS \\
Post operative ventilation $>14$ d & NS \\
Birth WAZ & NS \\
Gestation $<37$ wk & NS \\
\hline
\end{tabular}

Results of multivariable analysis using linear regression for risk factors associated with worse growth as measured by weight for age z-score. NS, Not significant $S I P$, stage 1 palliation; $E C M O$, extracorporeal membrane oxygenation; WAZ, weight for age $\mathrm{z}$-score.

growth can occur during the interstage period and is associated with improved outcomes in comparison with historical controls. ${ }^{9,12,13}$ A previous NPC-QIC study demonstrated significant institutional variation in the management and outcomes of interstage growth. The best growth was achieved at institutions using home monitoring, red flags for poor growth, frequent phone contact, and feeding evaluations after S1P. $^{24}$ Our current analysis demonstrates a decline in WAZ from birth to S1P discharge, however, the improvement in interstage growth previously demonstrated only in single-center studies is sustained across programs in this cohort, with an overall increase in WAZ during the interstage period. The early decline in WAZ can be anticipated as the perioperative period can be characterized by critical illness, fluid limitations, intolerance of enteral feeds, and higher metabolic demands. All of these problems are less likely to be experienced during the interstage period, allowing for this catch-up growth.

Although supplementation of oral intake with tube feeding may be required to achieve normal growth in a safe and effective manner, the ideal choice of feeding modality remains unclear. ${ }^{7,11,12}$ Hebson and colleagues ${ }^{10}$ retrospectively reviewed their experience with patients undergoing single-ventricle palliation between 2003 and 2010. They noted higher mortality in the cohort that underwent GT placement with or without Nissen fundoplication. Ultimately, they hypothesized that the need for GT may be a marker of an unknown risk factor for mortality. A secondary analysis of the Single Ventricle Reconstruction trial cohort found, using univariate analysis, that the inability to feed orally at the time of discharge was a risk factor for mortality. In contrast to the Hebson study, patients discharged with NG tubes were found to have higher mortality than those with GT. ${ }^{2}$ Previous work by 
Cross and colleagues ${ }^{22}$ using data from the NPC-QIC found that patients whose last documented feeding route was NG had a relative risk of 5.5 (1.5-20.1) for interstage death versus those receiving all oral or GT feeds. Using a single-center experience, Di Maria and colleagues compared patients with a single ventricle by feeding modality. They categorized patients into 3 groups (oral only, any NG intake, or any GT intake) based on feeding modality at discharge from S1P. Although they found no difference in interstage mortality, they did note those receiving supplementation of feedings were more likely to have undergone a Norwood procedure (vs shunt placement) and had a longer initial hospital course. They also noted that those receiving supplementation of feedings had significantly lower WAZ at discharge and the gap persisted until S2P. ${ }^{19}$

We found important differences in baseline characteristics between those requiring GT placement and the rest of the cohort; they had a greater decline in WAZ during the initial hospitalization, they had the lowest WAZ as a group at the time of S2P, they had more high-risk features including the presence of an extracardiac anomaly, and a more complicated hospital course with a higher incidence of preoperative intubation, vocal cord paralysis, ECMO, and prolonged postoperative ventilation. Data are unavailable as to whether 1 or more of these comorbidities were the predominant indications for GT placement. Furthermore, it is likely the early growth of these patients is affected by risk factors or altered physiology not captured in this analysis. The baseline differences between groups are the probable cause of the increased length of intubation and hospitalization seen in the NG only, GT only, and PO + GT groups. The older age at S2P in the GT only and GT + PO groups is likely multifactorial but may be in part a result of the longer initial hospitalization in those groups.

As a retrospective cohort, this study is subject to limitations in data collection. Only data collected by the NPC-QIC were available and these data may be influenced by center-specific practice, patient selection bias, and partial datasets for some patients. In addition, as a multiinstitution collaborative, there are variations in practice that may contribute to the differences seen. This is evident in the diagnosis of vocal cord injury; some institutions opt for universal screening, whereas others only evaluate symptomatic infants. Only those surviving to S2P were included in the analysis with potential skewing of mortality to favor 1 group and possibly occurring predominantly in those struggling to grow. We elected to use the modality of feeding at discharge for classification as this represented a point of stability for patients and parallels an intention-to-treat analysis; however, the timing and effect of interstage crossover in feeding modality is unknown.

\section{CONCLUSIONS}

Feeding modality did not affect interstage growth in patients after S1P, with all feeding modalities showing an increase in growth velocity during this period. Factors that negatively influence growth during the interstage period are a diagnosis of HLHS, vocal cord injury, and a lower target daily caloric intake at discharge from S1P. There are significant differences in the population requiring GTs placed that increase length of hospitalization after S1P. Continued focus on growth during neonatal hospitalization may identify additional risk factors for growth failure and ultimately improve outcomes.

\section{References}

1. Azakie T, Merklinger SL, McCrindle BW, Van Arsdell GS, Lee KJ, Benson LN, et al. Evolving strategies and improving outcomes of the modified Norwood procedure: a 10-year single-institution experience. Ann Thorac Surg. 2001;72: 1349-53.

2. Ghanayem NS, Allen KR, Tabbutt S, Atz AM, Clabby ML, Cooper DS, et al. Interstage mortality after the Norwood procedure: results of the multicenter single ventricle reconstruction trial. J Thorac Cardiovasc Surg. 2012;144: 896-906.

3. Srinivasan C, Sachdeva R, Morrow WR, Gossett J, Chipman CW, Imamura M, et al. Standardized management improves outcomes after the Norwood procedure. Congenit Heart Dis. 2009;4:329-37.

4. Hehir DA, Dominguez TE, Ballweg JA, Ravishankar C, Marino BS, Bird GL, et al. Risk factors for interstage death after stage 1 reconstruction of hypoplastic left heart syndrome and variants. J Thorac Cardiovasc Surg. 2008;136:94-9. 99.e1-3.

5. Furck AK, Uebing A, Hansen JH, Scheewe J, Jung O, Fischer G, et al. Outcome of the Norwood operation in patients with hypoplastic left heart syndrome: a 12-year single-center survey. J Thorac Cardiovasc Surg. 2010; 139:359-65.

6. Ghanayem NS, Tweddell JS, Hoffman GM, Mussatto K, Jaquiss RD. Optimal timing of the second stage of palliation for hypoplastic left heart syndrome facilitated through home monitoring, and the results of early cavopulmonary anastomosis. Cardiol Young. 2006;16(Suppl 1):61-6.

7. Anderson JB, Beekman RH III, Border WL, Kalkwarf HJ, Khoury PR, Uzark K, et al. Lower weight-for-age z score adversely affects hospital length of stay after the bidirectional Glenn procedure in 100 infants with a single ventricle. J Thorac Cardiovasc Surg. 2009;138:397-404.e1

8. Anderson JB, Kalkwarf HJ, Kehl JE, Eghtesady P, Marino BS. Low weight-forage z-score and infection risk after the Fontan procedure. Ann Thorac Surg. 2011; 91:1460-6.

9. Ghanayem NS, Hoffman GM, Mussatto KA, Cava JR, Frommelt PC, Rudd NA, et al. Home surveillance program prevents interstage mortality after the Norwood procedure. J Thorac Cardiovasc Surg. 2003;126:1367-77.

10. Hebson CL, Oster ME, Kirshbom PM, Clabby ML, Wulkan ML, Simsic JM Association of feeding modality with interstage mortality after single-ventricle palliation. J Thorac Cardiovasc Surg. 2012;144:173-7.

11. Jeffries HE, Wells WJ, Starnes VA, Wetzel RC, Moromisato DY. Gastrointestinal morbidity after Norwood palliation for hypoplastic left heart syndrome. Ann Thorac Surg. 2006;81:982-7.

12. Hehir DA, Rudd N, Slicker J, Mussatto KA, Simpson P, Li SH, et al. Normal interstage growth after the Norwood operation associated with interstage home monitoring. Pediatr Cardiol. 2012;33:1315-22.

13. Petit CJ, Fraser CD, Mattamal R, Slesnick TC, Cephus CE, Ocampo EC. The impact of a dedicated single-ventricle home-monitoring program on interstage somatic growth, interstage attrition, and 1-year survival. J Thorac Cardiovasc Surg. 2011;142:1358-66.

14. Williams RV, Zak V, Ravishankar C, Altmann K, Anderson J, Atz AM, et al. Factors affecting growth in infants with single ventricle physiology: a report from the pediatric heart network infant single ventricle trial. J Pediatr. 2011; 159:1017-22.e2.

15. Siehr SL, Norris JK, Bushnell JA, Ramamoorthy C, Reddy VM, Hanley FL, et al. Home monitoring program reduces interstage mortality after the modified Norwood procedure. J Thorac Cardiovasc Surg. 2014;147:718-23.e1. 
16. Pasquali SK, Ohye RG, Lu M, Kaltman J, Caldarone CA, Pizarro C, et al. Variation in perioperative care across centers for infants undergoing the Norwood procedure. J Thorac Cardiovasc Surg. 2012;144:915-21.

17. Anderson JB, Beekman RH 3rd, Eghtesady P, Kalkwarf HJ, Uzark K, Kehl JE, et al. Predictors of poor weight gain in infants with a single ventricle. J Pediatr. 2010;157:407-13, 413.e1.

18. Garcia X, Jaquiss RD, Imamura M, Swearingen CJ, Dassinger MS III, Sachdeva R. Preemptive gastrostomy tube placement after Norwood operation. J Pediatr. 2011;159:602-7.e1.

19. Di Maria MV, Glatz AC, Ravishankar C, Quartermain MD, Rush CH, Nance M, et al. Supplemental tube feeding does not mitigate weight loss in infants with shunt-dependent single-ventricle physiology. Pediatr Cardiol. 2013;34:1350-6.

20. Medoff-Cooper B, Irving SY, Marino BS, Garcia-Espana JF, Ravishankar C, Bird GL, et al. Weight change in infants with a functionally univentricular heart: from surgical intervention to hospital discharge. Cardiol Young. 2011;21:136-44.

21. Carlo WF, Carberry KE, Heinle JS, Morales DL, McKenzie ED, Fraser CD Jr, et al. Interstage attrition between bidirectional Glenn and Fontan palliation in children with hypoplastic left heart syndrome. J Thorac Cardiovasc Surg. 2011;142:511-6.

22. Cross RR, Harahsheh AS, McCarter R, Martin GR, for the National Pediatric Cardiology Quality Improvement Collaborative (NPC-QIC). Identified mortality risk factors associated with presentation, initial hospitalisation, and interstage period for the Norwood operation in a multi-centre registry: a report from the National Pediatric Cardiology-Quality Improvement Collaborative. Cardiol Young. February 6, 2013 [Epub ahead of print].

23. Kugler JD, Beekman Iii RH, Rosenthal GL, Jenkins KJ, Klitzner TS, Martin GR, et al. Development of a pediatric cardiology quality improvement collaborative: from inception to implementation. From the Joint Council on Congenita Heart Disease Quality Improvement Task Force. Congenit Heart Dis. 2009;4: 318-28.

24. Anderson JB, Iyer SB, Schidlow DN, Williams R, Varadarajan K, Horsley M et al. Variation in growth of infants with a single ventricle. J Pediatr. 2012 161:16-21.e1; quiz 21.e2-3.

25. Kelleher DK, Laussen P, Teixeira-Pinto A, Duggan C. Growth and correlates of nutritional status among infants with hypoplastic left heart syndrome (HLHS) after stage 1 Norwood procedure. Nutrition. 2006;22:237-44.

26. Srinivasan C, Jaquiss RD, Morrow WR, Frazier EA, Martin D, Imamura M, et al Impact of staged palliation on somatic growth in patients with hypoplastic left heart syndrome. Congenit Heart Dis. 2010;5:546-51.

27. Vogt KN, Manlhiot C, Van Arsdell G, Russell JL, Mital S, McCrindle BW. Somatic growth in children with single ventricle physiology impact of physiologic state. J Am Coll Cardiol. 2007;50:1876-83. 